\title{
CARE OF THE NEWBORN
}

\author{
By V. Mary Crosse, O.B.E., M.D.(Lond.), D.P.H. \\ Consultant Paediatrician, Birmingham Regional Hospital Board; \\ Lecturer in Department of Paediatrics and Child Health, University of Birmingham
}

The health of a new-born baby depends a great deal on the care of the mother during pregnancy and labour. A high standard of care during this period before birth can prevent or reduce the severity of such important neo-natal complications as prematurity, birth injury and asphyxia as well as many less common ones. In addition, much of the success in breast feeding depends on the preparation made during pregnancy.

Co-operation between the paediatrician and obstetrician is absolutely essential for good care of the new-born. In domiciliary practice, the family doctor is both obstetrician and paediatrician and there is no question as to where the duties of each begin and end. In hospital practice the relationship between the obstetrician and paediatrician was well put by Stabler (1952) when he said that the limits of paediatrics reached far into obstetrics and those of obstetrics far into paediatrics, and that the obstetrician and paediatrician must work as a team. Each obstetrician and paediatrician must work out their own method of co-operation, but in doing so care must be taken to provide adequate training in the care of the new-born for both paediatric and obstetric resident medical staff.

\section{Care Immediately after Birth}

\section{Resuscitation}

Asphyxia of the new-born is an emergency, and the need for a prepared plan of campaign must be recognized both for hospital and home deliveries. Any plan should include:

I. Clearing of the pharynx. A mucus catheter should be used for this purpose (the mouth should not be wiped out with gauze or lint). To be effective, the catheter must be fairly firm and have a large terminal opening and a suitable trap for mucus; more than one catheter should be available in case blocking occurs. Generally speaking, the best position for the baby during resuscitation is flat on the back with the head lowered and the neck not twisted; but after Caesarean section, it is usually necessary to place the whole child on an inclined plane with the head down in order to obtain effective draining of the air passages.
2. Prevention of heat loss. Undue loss of body heat should be avoided, but external heat should not be applied until any anoxia has been overcome because raising of the body temperature increases the oxygen requirements.

3. Administration of oxygen. If respiratory efforts are being made, oxygen can be given by face mask. A portable apparatus is now available for the administration of oxygen in the home (Waller and Morris, I953). Infrequent respirations can be increased by placing a hand under the child's chest and arching the spine forward at intervals (Crosse, 1952).

If no respiratory efforts are being made, oxygen may be given by the intragastric method, after aspiration of the stomach (Akerrén and Fürstenburg, 1950). The great value of this procedure is not sufficiently widely recognized. In the home, facilities for the administration of oxygen may not be available, but many a baby has been saved by mouth-to-mouth respiration.

In hospital practice, extra facilities for the stimulation of respiration may be available, e.g. a phrenic nerve stimulator (Cross and Roberts, I95I), or a positive pressure respirator (Donald and Lord, 1953).

4. Administration of suitable drugs. Coramine, cardiazol and lobeline are all effective in mild cases of apnoea where oxygen alone will stimulate respiration, i.e. when they are not really necessary; but in cases with marked hypoxia these drugs become ineffective and toxic; in addition lobeline is a cardiac depressant. There would appear to be little indication for the use of these drugs.

$\mathrm{N}$ allyl nor-morphine (' Lethidrone '), however, is useful if neo-natal asphyxia is due to morphia or pethidine.

In certain cases of persistent and severe shock, neuroplegic treatment (artificial hibernation) might be considered, and for this purpose chlorpromazine (' Largactil') is used with or without other narcotics.

Drugs should never be given into the cord because of the vascular complications which can result '(Mills, 1949). 
5. Administration of detergent aerosols. When atelectasis persists, detergent aerosols such as 'Alevaire' may prove helpful.

\section{Clamping of umbilical cord}

It is now generally believed that the cord should not be clamped until it has ceased to pulsate. By this delay, over $100 \mathrm{ml}$. of blood is transferred from the placenta to the infant. Haemolytic disease is, however, a contra-indication to this procedure.

\section{Care of the eyes}

It has become customary not to use antiseptic drops unless vaginal infection is present.

\section{Administration of vitamin $K$}

Because of the post-natal fall in the level of prothrombin, it is wise to give all new-born infants one dose of water soluble vitamin $\mathrm{K}$ at birth by intramuscular injection. There is a considerable weight of evidence to support the belief that this practice reduces the incidence of haemorrhagic disease of the new-born.

\section{Identification}

Public attention has recently been drawn to this problem. In order to avoid any possible error, each infant should be clearly marked at birth, if possible in two places in case one mark falls off or is removed in error. The best place is the ankle (name on a band of tape or batiste, but not written with marking ink because of the danger of aniline poisoning); a wrist band should be avoided because of the difficulty of feeling the radial pulse with such a band.

\section{Medical examination}

Every new-born baby should be examined by a doctor as soon as possible after delivery to ensure that congenital malformations amenable to surgical treatment are diagnosed immediately. This applies particularly to such conditions as tracheooseophageal fistula, diaphragmatic hernia or meconium ileus, in which the prognosis is improved by early treatment.

\section{Neonatal care General management}

It is essential that the correct mother-baby relationship is maintained. If the baby is born at home it is automatically kept with its mother unless there is some definite contra-indication.

In maternity units conditions vary, from hospital to hospital; in some the babies are only with their mothers at feeding times and spend the greater part of the day and night in nurseries, while in others the babies are kept with their mothers day and night. Generally speaking, the latter is the best, but each ward used in this way should not accommodate more than four mothers with theip babies, and a minimum of 120 sq. $\mathrm{ft}$. of floor space must be available for each mother and baby. I addition, extra accommodation must be provide for sick babies (with or without their mothers), fo항 healthy babies of sick mothers and for babies whō cry unduly at night. The daily care of infants i this type of accommodation provides an excellent demonstration for the mothers, and after a few days the mothers can participate in the care of theip own babies. 'Demand ' feeding is easy to manage in such wards.

If babies are accommodated in nurseries, $3 \frac{8}{8}$ sq. ft. of floor space should be allowed for eace baby and the cots must be either widely spaced ox; separated by low partitions so that the babies cannot sneeze or cough on to each other, and an isolatiog nursery must be provided for infected cases When babies are kept in nurseries, special arrange $\triangleq$ ments must be made for the education of the mother in the care of her baby before she leaves. the hospital.

It is important to treat the mother and child a a single unit. For this reason the general policy of the medical care of the new-born in hospital shoalf be formulated by the paediatrician in conjunction with the obstetrician. It is also important both obstetrician and paediatrician should know at once of any complication arising in either mothe or baby, and suitable arrangements must be madP to ensure that this is so.

\section{Feeding}

Breast feeding. Whenever possible babie should be breast fed. There has been some controversy as to whether 'schedule' feeding (feeding at regular intervals) or ' demand ' feeding gives the best results. Either method is satis factory if used with common sense. If regular. feeds are given three-hourly at first (the interva that the majority of infants choose when left to their own devices), if the feed can be given earlie when the baby continues to cry in spite of being ' changed ' or turned over, and if the interval cam. be lengthened to three and a half to four hourg when the baby consistently sleeps on after the usual feeding time, then there is nothing against feeding in this way and life may be more orderlog for the mother.

If ' demand' feeding is desired, care should be taken to ensure that the infant does not take ifs long sleep during the day because he will thent demand feeds at intervals all through the nightion Until the correct rhythm is established it is wise to wake the infant if he sleeps longer than foo hours during the day time. 
Whichever method is chosen, both breasts must be used at each feed in order to prevent a building up of tension which reduces the supply of milk. To prevent injury to the nipples (which may lead to mastitis) the baby must not be kept sucking an empty breast, but be allowed to stop feeding as soon as he is satisfied. Short periods at the breast are particularly important during the first few days of life before the milk ' comes in.' After the milk has come in time must be allowed for the flow to be initiated; but the breasts are still emptied fairly quickly if the infant sucks well. The practice of offering routine bottle-feeds of water or milk to new-born infants before the mothers' milk comes in is a bad one. It gives no lasting advantage to the infant and is a possible source of infection. The administration of extra fluid should be reserved for the occasional infant who develops dehydration fever.

After the first few days infants should be weighed at regular intervals. An initial average loss of $\mathrm{I}$ or $\mathrm{I} \frac{1}{2} \mathrm{oz}$. per $\mathrm{lb}$. of birth weight may be expected, but the birth weight should be regained by the seventh to tenth day; after this any baby (weighing more than $3 \frac{1}{2} \mathrm{lb}$. at birth) should gain about I oz. daily, irrespective of the birth weight, and some gain more.

Over-feeding is rare among infants on 'demand ' feeding, and it should not occur among infants on a regular schedule if they are allowed to stop sucking when satisfied, and if the interval between feeds is lengthened when the baby sleeps on regularly past the feeding times. Under-feeding may occur in either group if the supply of milk is poor, but it is less likely to occur with ' demand ' feeding because a healthy infant automatically demands extra feeds. A deficient weight gain in a baby fed on a regular schedule can be improved by increasing the number of feeds during the 24 hours, but a complement after each feed may be necessary if the milk supply remains poor. If the picture is complicated by vomiting or loose stools, it may be necessary to 'test weigh' for 24 hours in order to discover whether the infant is taking too much or too little. Experiments show that the average daily quantity per pound, taken by a healthy new-born baby, reaches one ounce by the fourth day, two ounces by the eighth day, and two and a half ounces by the tenth day, i.e. a daily increase of a quarter of an ounce per pound of birth weight until the tenth day of life. 'Testweighing' is of little use before the fifth day. If vomiting is absent, and the stools are normal, ' test-weighing' is unnecessary because the child is obviously getting insufficient for his needs.

In some cases of under-feeding, the supply of milk is adequate but the baby's suction is poor. In such a situation, the infants should be comple- mented with milk expressed after the previous feed, as this keeps the feeding time within normal limits. When the secretion of milk is poor, special ${ }^{\circ}$ measures should be taken to increase the supply $\stackrel{.}{-}$ by diet, rest, iodine tablets, arm exercises, re $\overrightarrow{\vec{m}}$ assurance, etc.

Artificial feeding. If a mother is unfit to breast등 feed her baby then a cows' milk formula must be $\frac{\bar{c}}{\mathrm{c}}$. given. A full cream dried milk mixture made up $\widehat{\phi}_{\bar{\sigma}}$ with one measure of milk powder to one and $a$ 일 half ounces of water with the addition of onew drachm of granulated sugar to every two ounces $\vec{\circ}$ of the mixture (protein 2.2 per cent., fat 2.2 percent., carbohydrates 9.2 per cent., calories 20 perc్ ounce) supplies the full amount of cows' milks protein that is required for growth (except in the case of marasmic or premature infants) and the maximum amount of fat that is likely to be utilised: the high percentage of sugar ensures that all the protein will be available for growth. If evaporated milk is preferred, one part of evaporated milk to $\oplus$ three parts of water, with the addition of one drachm of sugar to every two ounces of the mixture? has a similar composition. Both these mixtures $\vec{c}$ provide 20 calories to the ounce and are suitable for ' demand' feeding.

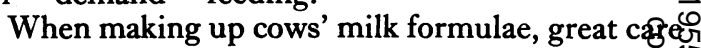
must be taken to ensure that the correct amou $\mathrm{u}^{\mathrm{N}}$ of milk powder and water are used: with too mus water or too little milk powder, the child's thi will be satisfied before sufficient calories have beent taken; and with too little water or too much:


or may perhaps develop 'milk powder fever (Royer, I954). Milk powder should be measure\& in the special measures provided by the makers? of the milk food (level and well packed), and water़ and evaporated milk in measures marked if ounces or tablespoons (and not in domestic table 3 . spoons which contain at least two tablespoonsfuls; of fluid!). It is hoped that special measures for one drachm of sugar may soon be provided by the makers of milk food, but until then, the measure provided for the milk powder contains approxio mately two drachms of sugar if slightly heaped

As already mentioned, experiments show that. the breast fed infant only reaches the daily average of two and a half ounces per pound per day by the tenth day. It is, therefore, wise to limit the quantity of formula offered to a bottle-fed babł during the first ten days of life: slightly more than the average daily requirements can be offered and the infant allowed to take as much of this as if requires. "During the first few days of life, the standard mixtures mentioned should be given diluted.

Vitamins. An adequate dosage of vitamin $\vec{\Phi}$ should be ensured by giving orange juice and co $\frac{\alpha}{0}$ 
liver oil. The possibilities of overdosage with vitamin $\mathrm{D}$ has been pointed out by Creery and Neill (1954). Vitamin D is added to dried and evaporated milk, and an allowance should be made for this.

\section{Prevention of infection}

Source of infection. Healthy infants must be protected from any possible source of infection, e.g. from infected or potentially infected infants, and from infected attendants and potentially infected visitors or relations.

Spread of infection. Spread by dust, droplet and contact, must be reduced by laying of dust, correct wearing of adequate masks, spacing of cots, elimination of flies, and good barrier nursing, i.e. cotside care instead of changing tables, sterilised bathing bowls instead of fixed baths, protection of weighing scales, provision of individual equipment whenever possible, use of gowns, and above all, careful hand washing and drying.

Sites of entry. The chief sites of entry for infection must be protected, i.e. umbilical wound, skin abrasions and mucous membranes.

The modern tendency to leave the umbilical wound without a dressing is just as dangerous as applying a dressing and leaving it untouched for days.

Many types of skin care have been tried and experience shows that the least amount of infection occurs when the infants are left unbathed. Thick patches of vernix may be removed with sterile oil, but the remainder is allowed to dry and fall off. From the fifth day onwards, the infant may be bathed on alternative days in order to teach the mother how to bath her infant.

The mouth should never be treated unless infection has occurred, and the digestive tract must be protected by careful sterilisation of formulae, bottles and teats. The nose may be cleared when necessary by the use of nasal drops to induce sneezing, and the respiratory tract must be protected by the use of masks by all attendants.

Use of antibiotics. Antibiotics should be used in potentially infected cases, and definite infections must be treated early if the results are to be good.

Home and hospital infections. In the home, respiratory infections are the chief danger, and precautions should be taken to prevent undue exposure of the baby to relatives and friends. In hospital practice, the danger of contact infection is greater than in the home (Crosse and Mackintosh, I953).

\section{Prevention of suffocation.}

A pillow should never be used for the new-born, and the infant should never be left with a bottle气 'propped' in its mouth. Feeding bottles should $\frac{\mathbb{\Phi}}{3}$ always be held.

\section{Circumcision}

Gairdner (1954), has shown that a non-retractileo prepuce is normal in the infant. There areo probably only three indications for circumcision $\overline{\frac{\bar{s}}{5}}$ in the new-born: (I) inability to pass urine because of phimosis, (2) Jewish ritual circumcision ando (3) desire of parents. Because of the possibles risk of infection, circumcision should only be $\overrightarrow{0}$ performed for the first of these indications while $\overrightarrow{\vec{\omega}}$ the baby is in a maternity hospital, and thiso indication is extremely rare.

\section{Facilities for emergency treatment}

In both hospital and home, facilities must bej available for the giving of injections, and for the clearing of air passages. In hospital, facilities $\omega_{\perp}$ must also be available for the administration of oxygen.

\section{Care prior to discharge}

Before a mother and baby are discharged from $\rightarrow$ hospital, or before the domiciliary midwife lea\&sol the home, the following are important:

I. The mother must know how to care for infant.

2. The infant should be examined by a doctoro to ensure that abnormal signs have not developed since the medical examination at birth. This is@ especially important in regard to late-developing $\overrightarrow{\widehat{O}}$ heart murmurs.

3. The Public Health Department should be? given all particulars of the birth so that the Healtho Visitor can take over the supervision of the mothero and child at home. If the child is born in hospital, the family doctor must be notified of its discharge, and given full particulars of the birth and neo natal period.

\section{BIBLIOGRAPHY}

ÅKERRÉN, Y., and FURSTENBLRG, N. (1950), 7. Obstet Gynaec., 57, 705.

CREERY, R. D. G., and NEILL, D. W. (1954), Lancet, 2, I1 24. CROSS, K. W., and ROBERTS, P. W. (1951), Brit.med. F., i, 1043 N CROSSE; V. M. (1952), The Premature Baby,' Churchill, London ' p. 85 .

CROSSE, V. M. and MACKINTOSH, J. M. (1953), Brit. med. F. స్ i, 1374 .

DONALD, I., and LORD, J. ( ( 953), Lancet, i, 9.

GAIRDNER, D. (1954), 'Recent Advances in Paediatrics, Churchili, London, p. 96.

LACOMME, M., CHABRUN, J., BOREAU, T., and DAVID, G@ (1954), 'Neonatal Studies,' 3, 3.

MILLS, W. G. (1949), Brit. med. F., ii, 464.

ROYER, P. (1954), ' Neonatal Studies,' 3, 177.

STABLER, F. E., F. Obstet. Gynaec. (I 952), 59, 666.

WALLER, H. K., and MORRIS, D. (I953), Lancet, ii, 95 r. 